\title{
Smart Cities \& 21st Century Economic Development \& Welfare Holistic Approach Towards a Roadmap Strategy Development for RAK Emirate
}

\author{
Imad Eddine Oubiri* \\ RAK Chamber of Commerce and Industry, Ras Al Khaimah, UAE
}

\begin{abstract}
Modern economic concepts and models are nowadays abounding, thus creating a challenge in keeping pace with the global economic and technological developments, for both institutions and individuals, often failing to grasp the true meanings and purposes of the latter; thus receding chances for economic communities to make use of the sound scientific content therein, fair value, great benefits and implied objectives to achieve economic development and welfare. In recent years, and after the spread of some the concepts such as "sustainability", "clean and green energy", "egovernment"; the "Smart" concept is nowadays strongly imposing itself in the local scene, after UAE Federal Government and Dubai Emirate have adopted and embarked onto "Smart Progressive" plan implementation. Candid man-of-the-street assumptions would inevitably and systematically link the concept to applications for smart phones and mobile systems and the exploitation of technological resources in everyday life. Whereas, in fact this is only a part of a whole integrated and wide-ranging economic system in which technology plays a pivotal role alongside with several other most prominent and crucial factors. The present paper deals with introduction to the "Smart" economic model implementation in our City of the future, with focus on criteria, requirements, indicators and role and contribution of citizens, government and institutions, aiming at shedding the light onto a hot topic with critical impact on present and future holistic economic action plans.
\end{abstract}

Keywords: Smart City, Technology Integration, Infrastructure Integration, Strategy Development

\section{Motivation of Research}

Today, Ras Al Khaimah economy is being recognized as one of the fastest growing economies in the region, with great potentials that entitle it to become one the strongest in the UAE and MENA region. The strategic geographical location it enjoys in addition to the existing resources as well as its promising current economic outputs, further consolidate these positive indications.

However, to be able to keep pace with the current local economy rapid growth and keep abreast with the global developments and competitiveness, it has become a necessity for RAK to position itself and equally define a clear roadmap

${ }^{*}$ Corresponding author

E-mail: imad@rakchamber.ae

(C) 2015 International Association for Sharing Knowledge and Sustainability

DOI: $10.5383 /$ swes.7.02.003 and develop a consistent strategy enabling commendation and implementation of an economic action plan considering its present status, upcoming transitional stage and its projection into the future. Furthermore, and given that some specialists and researchers had already forecasted a bright future for RAK in ICT, it is believed that this element would add to its potential for becoming one of the smart cities of the future. Recent practices to make cities better for living have become successful cases for new city development strategies, and Ras Al Khaimah would need to ultimately learn from the successfully progressive cases [Table1\&3]. Through this research, we attempt to present with some of the elements that would tentatively give an inclusive insight into means of development to be adapted for the RAK Smart City of the future. 


\section{Introduction}

The multiplicity of contemporary theories and concepts on elements of a "smart city" is helping nations draw a tailored strategy roadmap and vision to keep abreast with the rapid global economic continuous changes and developments, adapt the adequate factors and indicators matching their specific needs and converting them into action plans and real-time strategies, monitor and mobilize economic essentials necessary to the transition and transformation process into a "smart economy" and measuring progress and development.

Nonetheless, this is still considered a major challenge for most nations of the world, as with the rapid increase of the urban population worldwide, cities face a variety of risks, concerns, and problems; for example, physical risks such as deteriorating conditions in ecosystem and mobility, and economic risks such as unemployment. The unprecedented rate of urban growth creates urgency to finding smarter ways to manage the accompanying challenges. And as some cities are identified to successfully operate in a smarter way, and to solve concerns, we need to learn from progressive practices of those who gained progress in the field [Table1\&3]. It is obvious that modern nations are faced with an era presenting with increasing necessities and depleting resources, therefore it has become essential to find smarter solutions, through real-time data collection and analysis to keep pace with the rapid changes of today, addressing contemporary issues and planning for the future.

\section{Definitions}

\subsection{Smart City}

In general terms, "smart city" would be defined as an integrated urban environment in which technology plays a major role alongside with numerous other factors. And according to some definitions, and in this specific context, the term "smart" would rather more appropriately refer to "userfriendly" rather than simply intelligent or digital. Therefore, a smart city would be more properly defined as an integrated technology user-friendly urban environment. This is said, specialists mostly agree on a framework and specific requirements that must be met to attain this goal of the future and achieve the desired economic welfare.[Table2]. From table below we could essentially retain that smart city is about interconnectedness and monitoring of infrastructure components, a well-performing economy through a combination of endowments and aware citizens, accessibility to public information and services through ICT.
Table 1. The List of Smart Cities

\begin{tabular}{|c|c|}
\hline Region & Cities \\
\hline Asia & $\begin{array}{l}\text { Bangalore (India); Chongging (China); Doha (Qatar); } \\
\text { Gangnam District, Seoul (Korea); Hong Kong; HwaSeong- } \\
\text { DongTan (Korea); Hyderabad (India); Ichikawa (Japan); } \\
\text { Jaipur, Rajasthan (India); Jia Ding (China); Kabul } \\
\text { (Afghanistan); Mitaka (Japan); Shanghai (China); Seoul } \\
\text { (Korea); Singapore; Suwon (Korea); Taipei (Taiwan); } \\
\text { Taoyuan County (Taiwan); Tel Aviv (Israel); Tianjin (China); } \\
\text { Yokosuka (Japan) }\end{array}$ \\
\hline Africa & $\begin{array}{l}\text { Cape Town (South Africa); Nelson Mandela Bay (South } \\
\text { Africa) }\end{array}$ \\
\hline Europe & $\begin{array}{l}\text { Besançon (France); Birmingham (UK); Dundee, Scotland } \\
\text { (UK); Eindhoven (Netherlands); Glasgow, Scotland (UK); } \\
\text { Hammarby Sjostad (Sweden); Issy-les-Moulineaux (France); } \\
\text { Karlskrona (Sweden); Malta (Malta); Manchester (UK); } \\
\text { Reykjavik (Iceland); Sopron (Hungary); Stockholm (Sweden); } \\
\text { Tallinn (Estonia); Sunderland (UK); Trikala (Greece) }\end{array}$ \\
\hline North America & $\begin{array}{l}\text { US: Allbany (New York); Ashland (Oregon); Arlington County } \\
\text { (Virginia); Bettendorf (lowa); Bristol (Nirginia); Chattanooga } \\
\text { (Tennessee); Cleveland (Ohio); Corpus Christi (Texas); } \\
\text { Dakota County (Minnesota); Danville (Virginia); Dublin } \\
\text { (Ohio); Florida High Tech Corridor, LaGrange (Georgia); } \\
\text { Northeast Ohio; Loma Linda (California); Riverside } \\
\text { (Calfornia); San Francisco; Spokane (Washington); } \\
\text { Westchester County (New York); Winston-Salem (Carolina) } \\
\text { Canada: Burlington (Ontario); Calgary (Alberta); Edmonton } \\
\text { (Alberta); Fredericton (New Brunswick); Kenora (Ontario); } \\
\text { Moncton (New Brunswick); Ottawa (Ontario); Quebec City } \\
\text { (Quebec); Strattord (Ontario); Toronto (Ontario); Vancouver } \\
\text { (British Columbia); Waterloo (Ontario); Westem Valley (Nova } \\
\text { Scotia); Windsor-Essex (Ontario); Winnipeg (Manitoba) }\end{array}$ \\
\hline $\begin{array}{l}\text { Middle/South } \\
\text { America } \\
\end{array}$ & $\begin{array}{l}\text { Barceloneta (Puerto Rico); Curitba, Paraná (Brazil); Pirai } \\
\text { (Brazil); Porto Alegre (Brazil) }\end{array}$ \\
\hline Oceania & $\begin{array}{l}\text { Ballarat (Australia); Gold Coast City (Australia); I Ipswich, } \\
\text { Queensland (Australia); State of Victoria (Australia); } \\
\text { Whittlesea, Victoria (Australia) }\end{array}$ \\
\hline \multicolumn{2}{|l|}{ Source: } \\
\hline . & elligentcommunity.orcindex oho? submen \\
\hline
\end{tabular}

Table1: List of Global Smart Cities (Source: Conceptualizing Smart City with Dimensions of Technology, People, and Institutions. Taewoo Nam \& Theresa A. Pardo Center for Technology in Government, University at Albany, State University of New York, U.S.) \{Tnam, tpardo\}@ctg.albany.edu 
Table 2. Definitions of Smart City

\section{Definition}

"The use of Smart Computing technologies to make the critical infrastructure components and services of a city-which include city administration, education, healthcare, public safety, real estate, transportation, and utilities-more intelligent, interconnected, and efficient."

"A city well performing in a forward-looking way in economy, people, governance, mobility, environment, and living, built on the smart combination of endowments and activities of self-decisive, independent and aware citizens."

A city striving to make itself "smarter" (more efficient, sustainable, equitable, and livable)

A city that monitors and integrates conditions of all of its critical infrastructures, including roads, bridges, tunnels, rails, subways, airports, seaports, communications, water, power, even major buildings, can better optimize its resources, plan its preventive maintenance activities, and monitor security aspects while maximizing services to its citizens.

An instrumented, interconnected, and intelligent city. Instrumentation enables the capture and integration of live realworld data through the use of sensors, kiosks, meters, personal devices, appliances, cameras, smart phones, implanted medical devices, the web, and other similar data-acquisition systems, including social networks as networks of human sensors. Interconnected means the integration of those data into an enterprise computing platform and the communication of such information among the various city services. Intelligent refers to the inclusion of complex analytics, modeling, optimization, and visualization in the operational business processes to make better operational decisions.

"A city that gives inspiration, shares culture, knowledge, and life, a city that motivates its inhabitants to create and flourish in their own lives"

"A city where the ICT strengthen the freedom of speech and the accessibility to public information and services"

Table2: Definition of Smart City (Source: Conceptualizing Smart City with Dimensions of Technology, People, and Institutions. Taewoo Nam \& Theresa A. Pardo Center for Technology in Government, University at Albany, State University of New York, U.S.) \{tnam,tpardo\}@ctg.albany.edu

\subsection{Smart Economy}

Smart Economy is based on a strategy to drive economic growth through knowledge, innovation and creativity. It's about extracting 'more for less'. It means using technology and innovative ways of working to increase productivity without damaging the quality of life or the environment. The pilots for smart economy are those behind fostering entrepreneurship and innovation, local and global interconnectedness, avant-garde education, inclusive society, health and safety, green urban planning, and open data and transparency from an interactive performing e-government [Figure1].The smart economy combines leadership and innovation by means of the so-called "economy of ideas" and at the same time emphasizes on promoting high-quality of life, improving energy security, stimulating social inclusiveness and protecting the environment. The most successful economies of the future will be those that will manage to achieve this combination of critical components [Figure1]. Among essential characteristics to be retained and focused on are high-quality education and scientific research funded by the public sector, provision of tax incentives for companies, including tax breaks; and a strong high-quality infrastructure based on local and international interconnectedness, availability of excellent public information and services, more specifically health care.

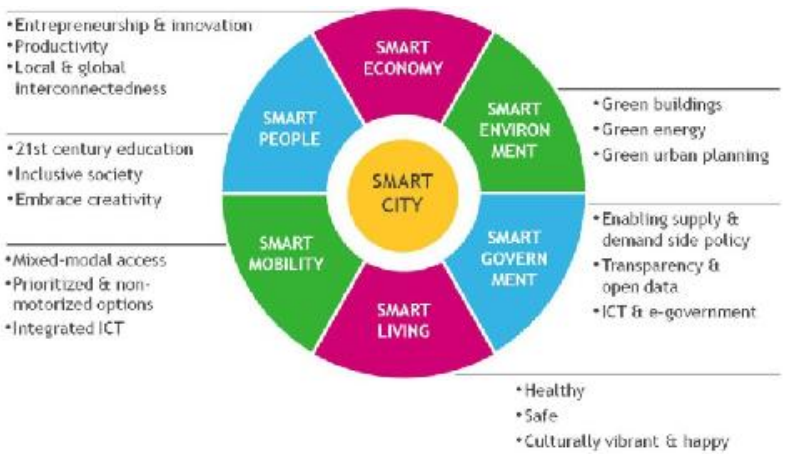

Figure1: Pilots \& Drivers for Smart City Development (Web Navigant Source)

\section{Transformation into Smart City}

One may argue that this conception is new to the world, but in fact this is backdating to as early as the 70's and even before. It is a fact that some countries had gone a long way in the process of conceptualization and transformation, and have already taken position on the global economic map with regard to planning and implementation, and some of them are today topping up lists of most efficient smart cities in the world [Table1\&3]. There are several factors that would qualify one city more than another into the swift and rapid transformation process: government policy making, geographic location, connectivity of infrastructure, human empowerment, population inclusion and openness, and ICT interactivity disposition. One major factor to highlight is the policy context which is critical to driving the process of conversion in appropriate ways. Hence, an innovative government stresses the change in policies and regulations, because a government cannot innovate without subsequent changes in the institutional context and non-technical urban issues, leading to creating conditions enabling urban development.

\subsection{Stages in Smart City Development}

Development into smart city entails assessment and mitigation of current components and envisaging meeting the necessary prerequisites for change in a 3-dimensional way encompassing the rigorous criteria in elements described above [Figure1]. Therefore, randomness in urbanization, inconsistency in policy making, unmonitored plans and unclear visions would be enemy to it. Progress towards the desired transformation lays in the steps undertaken in turning ad hoc unilateral departmental projects into proactive collaborative interdepartmental ones, involving all stakeholders aligned around an amalgamated strategy, defining barriers and valuating opportunities. The practice of the later would 
subsequently lead to flow of information, integration in strategy and processes implementation; in turn enabling performance management and progress evaluation in addition to sound governance. It goes without saying that once applied the process is to ultimately lead to the achievement of desired results, for instance a sustainable ctiywide platform in place, continuously evolving strategy, governance allying autonomy and integration into a system that is to produce superior outcomes and deliver differentiation[Figure2]. And that is eventually what makes a vibrant smart city.

Stages in Smart City Development

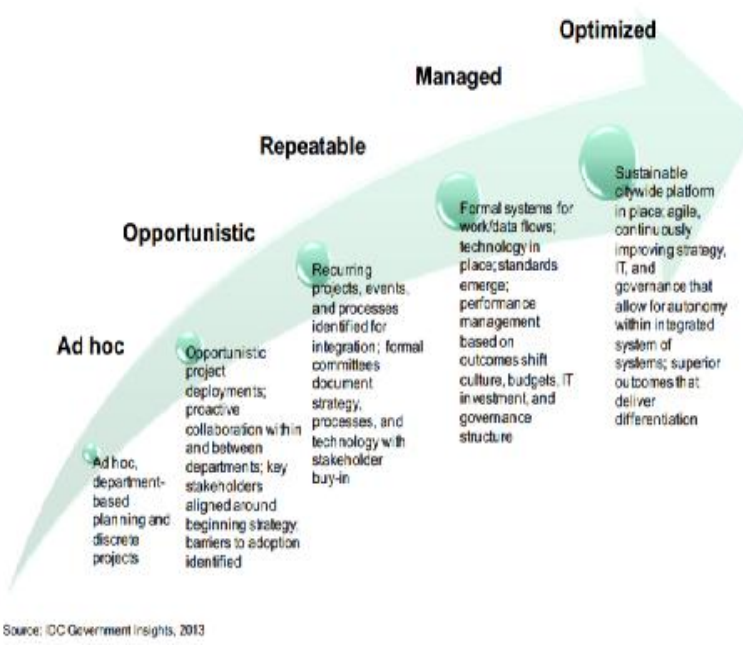

Figure2: Stages for Smart City Development (Source: IDC Government Insights, 2013)

\subsection{Ranking and Benchmarking}

Global competitiveness is a natural stimulus for development. The use of this method not only allows international standardization, positioning steering progress monitoring, but furthermore - and in many ways - healthy competition, selfevaluation, identification of strengths and weaknesses and more importantly knowledge transfer. It is essential for a developing city to benchmark with peer advanced cities worldwide having a certain similarity in economic particulars, as there is no magic solution for becoming a smart city, "Each city has to respond to its own unique environment and will be smart in its own way". "You have to see smart as an aspirational concept"[Erick Woods, GreenBiz]. It is worthwhile noting that some smaller cities have shown very progressive outcomes in comparison to larger metropolitans, thus indicating that size in this specific context is far from being the most relevant criterion for valuation. This is said, this process would not be made possible without the existence of a fair and sound integrated local system for data compilation susceptible of measuring and evaluating outputs. Hence, the need for the creation of a local integrated pool and system for data and information collection, analysis and dissemination. Below, Table3 featuring sample for European smart cities ranking.

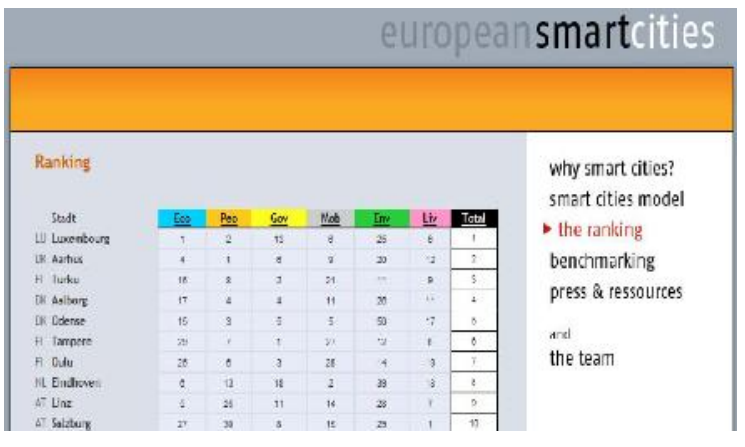

Table3: European Smart Cities (Source: ACE | SMART CITIES RANKING)

\subsection{Spending and Outlays Forecast on Smart Cities}

The smart concept is gaining train all over the globe and many governments of cities that adopted future plans for their smart conceptualization, have already projected their spending on technology infrastructure over the next decades with viable estimations. As part of the process and as for any project requirement, early budgeting is essential for a successful implementation. Consequently, comprehensive feasibility studies on investments over the planned or projected developments for smart city are necessary as part of the overall strategy and vision. [Figure3]

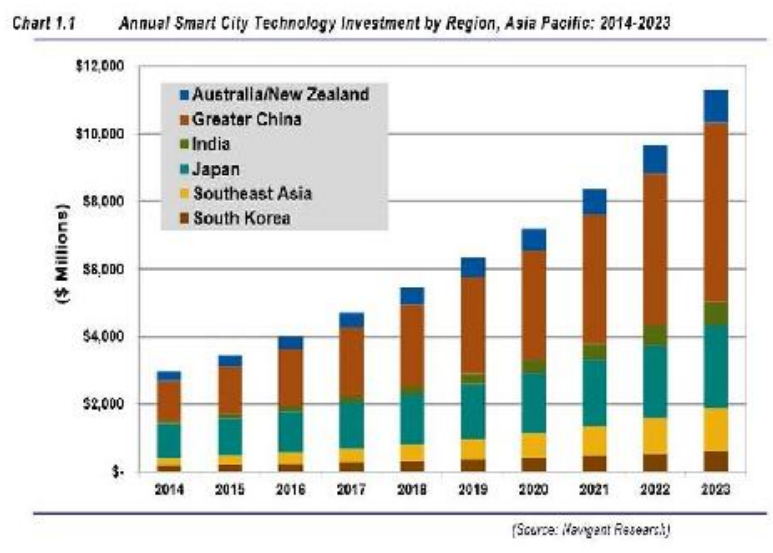

Figure3: Spending on Smart Cities (Navigant Research)

\subsection{Capitalizing on Human Assets}

Neither Technology nor leadership and policy making alone would suffice in the transformation process into smart city; nor will innovation be made possible without the contribution of people. The emphasis on human infrastructure and social learning and education is therefore a must. "Progressive Smart" should start with people from the human capital side, rather than blindly believing that ICT itself can automatically transform and improve cities [GreenBiz]. It is important to consider approaches to foster awareness, education and adherence of citizens. Social learning in making smarter choices in everyday life, exploitation of ICT in an efficient manner, energy saving, considerate behavior for environment protection, and better choices in urban mobility, are essential perquisites for the process. 


\section{Concluding Remarks}

We expect that this minimalistic paper will contribute to future studies, instigate interest of both local constitutions and decision makers to further extend research in the field. As we elaborated on some conceptual dimensions of smart city, the concept is an organic connection among technological, human, and institutional components. From illustration of the different transformational stages for smart city, explaining the various dynamics behind the process and discussing the various components, highlighting the significance of city positioning and benchmarking and stressing on the human infrastructure prominence for smart economy achievement; we aimed at showcasing factors of interest that might be relevant for strategy development, projections \& planning of Ras AlKahimah Smart City of the future.

\section{Recommendations}

We would refer to a sound citation made above: "Each city has to respond to its own unique environment and will be smart in its own way". "You have to see smart as an aspirational concept". [Erick Woods, GreenBiz]. Research and studies would in no manner whatsoever prescribe and preconize a "one-size-fits-all" model for implementation, as each city would have to consider its own characteristics, requirements and aspirations, tailor its "smart progressive" strategy and plans for development and transformation.

In our specific local context of Ras Al Khaimah, and considering the comprehensive economic features, notably the current rise of infrastructural developments and progressive urban transformation taking place and witnessed with the affluence of investments and projects; we believe it is a seeable opportunity for the economic community to consider RAK's Smart potential and instigate deep research into the subject matter as early as possible and create a local integrated pool and system for data compilation to assess and mitigate current components and envisage meeting the necessary prerequisites for change, turning ad hoc unilateral departmental projects into proactive collaborative interdepartmental ones, involving all stakeholders aligned around an amalgamated strategy to achieve the Smart RAK.

\section{References}

Understanding Smart Cities: An Integrative Framework

Hafedh Chourabi

Université Laval, Canada

hafedh.chourabi.1@ulaval.ca

Taewoo Nam

University at Albany, SUNY

tnam@albany.edu

Shawn Walker

University of Washington

stw3@uw.edu

J. Ramon Gil-Garcia

Centro de Investigación y

Docencia Económicas, Mexico joseramon.gil@cide.edu

\author{
Sehl Mellouli \\ Université Laval, Canada \\ sehl.mellouli@sio.ulaval.ca \\ Karine Nahon \\ University of Washington \\ karineb@uw.edu \\ Theresa A. Pardo \\ Center for Technology in Government, \\ University at Albany, SUNY \\ tpardo@ctg.albany.edu \\ Hans Jochen Scholl \\ University of Washington \\ jscholl@uw.edu
}

Conceptualizing Smart City with Dimensions of

Technology, People, and Institutions

Taewoo Nam \& Theresa A. Pardo

Center for Technology in Government

University at Albany, State University of New York, U.S.

$\{$ tnam,tpardo $\} @$ ctg.albany.edu

\section{Transnationalism From Below}

Michael Peter Smith

Luis Eduardo Guarnizo

Editors

Comparative Urban and Community Research V6 - 1998

New Brunswick: Transaction Publishers

Smart Cities:

Explaining the Relationship between City Growth

and Human Capital

Jesse M. Shapiro

Harvard University

June 19, 2003

\section{Smart Cities Ranking: An Effective Instrument For The Positioning Of Cities}

GIFFINGER, Rudolf1

GUDRUN, Haindlmaier2

Paper first received: 7-9-2009 Final form: 25-1-2010 
Developing a Policy Roadmap for Smart Cities and the Future Internet

Nicos KOMNINOS1, Hans SCHAFFERS2, Marc PALLOT3

1Urenio, Aristotle University of Thessaloniki, 54124 Greece

Email: komninos@urenio.org

2ESoCE Net, Waterstraat 5, 7201 HM Zutphen, The

Netherlands

Email: hschaffers@esoce.net

3INRIA Sophia Antipolis - Méditerranée, AxIS Team, 06902

France

Email: marc.pallot@inria.fr

\section{GreenBiz}

http://www.greenbiz.com/news/2013/03/06/growth-smartcities

Smart city - Wikipedia, the free encyclopedia http://en.wikipedia.org/wiki/Smart_city

european smart cities - The smart city model http://www.smart-cities.eu/model.html

Navigant Research

http://www.navigantresearch.com/ 